\title{
Experimental Study on Plastic Strips and EPS Beads Reinforced Bottom Ash Based Material
}

\author{
B. Ram Rathan Lal ${ }^{1} \cdot$ Sonali S. Nawkhare ${ }^{1}$
}

Received: 1 June 2016/Accepted: 3 August 2016/Published online: 10 August 2016

(C) Springer International Publishing Switzerland 2016

\begin{abstract}
This paper pertains to the results of experimental studies carried out on newly developed geomaterial prepared by blending bottom ash with expanded polystyrene (EPS) beads, strips cut from the used and waste plastic water bottle and a binder such as ordinary Portland cement. The mix ratios used in the experimental study were 0.2 , $0.4,0.6,0.8$ and $1.0 \%$. The plastic strips were used in two different aspect ratios 10 and 5 with different mix proportions with respect to bottom ash 1,2 and $3 \%$. The cement to bottom ash $(C / B A)$ ratio was considered as $10 \%$. Cylindrical specimen of dimensions $50 \mathrm{~mm}$ diameter and $100 \mathrm{~mm}$ height was used to evaluating the compressive strength of the geomaterial for curing periods of 7,14 and 28 days. The effect of mix ratio, percentage of plastic strips and curing period on the compressive strength, stressstrain behaviour, density and initial tangent modulus of the geomaterial were studied and results are incorporated in the paper. Test results indicated that for a particular mix ratio, the compressive strength increased with increasing aspect ratio and percentages of plastic strips. For particular curing period, the compressive strength increased with decreasing mix ratio values. For all the mix ratios, maximum compressive strength of $293.3 \mathrm{kPa}$ was observed for aspect ratio of 5 and 28 days of curing period when plastic strip percentage was $3 \%$. The relationship between compressive stress and strain was observed to be nonlinear for all the mix ratios and curing periods. The density of
\end{abstract}

B. Ram Rathan Lal

rathan_lal@yahoo.com

Sonali S. Nawkhare

sona.naw93@gmail.com

1 Department of Civil Engineering, K.I.T.S., Ramtek, Nagpur, MS 441106, India geomaterial reduced from 798 to $544 \mathrm{~kg} / \mathrm{m}^{3}$ with the addition of EPS beads from 0.2 to $1.0 \%$. The initial tangent modulus of geomaterial increased with increasing percentages of plastic strips. The utilization of bottom ash and waste plastic bottle strips can solve its disposal problem in environmental friendly manner in the direction of sustainable development.

Keywords Bottom ash - Waste plastic water bottle . Geomaterial $\cdot$ Mix ratio $\cdot$ Compressive strength $\cdot$ Density Sustainable development

\section{Introduction}

The construction industry is the largest consumer of conventional materials which led to its depletion. This situation led us to explore alternative material and one of the materials which has shown substantial guarantee as building material is bottom ash. In thermal power plants, the burning of pulverized coal produces huge amount of coal ashes which includes fly ash and bottom ash. The large scale establishment of hydroelectric power plants or nuclear power plants is receiving lesser priority due to their inherent limitations. So, the coal based thermal power plants are being installed worldwide which results in the production of huge quantity of coal ashes [1]. Bottom ash is a part of the noncombustible residue of combustion process in a furnace. Bottom ash is used as a foundation material, road and construction filler material, in noise barriers, as a capping layer on landfill sites [2].

The continuous increase in the use of plastic bottled drinking water over the last few decades has been resulting in astonish rise of plastic waste in the municipal solid waste across many cities in India. Recycling of this plastic waste 
has become one of the major challenges in India. It was reported by [3] that the estimated production of plastic in India was 8 million tons in a year 2008 and globally this amount is $\mathbf{1 5 0}$ million tons. It is non-biodegradable material hence for many years it remains on the planet as a waste material. Lot of efforts need to be taken to utilize this plastic waste in other ways.

Expanded polystyrene (EPS) beads are used to prepare light weight fill materials. Before the EPS blocks production, EPS beads are manufactured. EPS beads are rounded grains, white in color and they are produced either in factories or at the construction sites [4]. EPS beads consist of polystyrene and dissolved pentane (the blowing agent). The beads may also contain a fire-retardant additive [5]. It is non-biodegradable material and chemically inert in both soil and water [6]. EPS beads do not absorb water as it is made up of closed cell structure [7]. It is highly compressible material available in different types for specific purpose. Bottom ash and EPS beads based geomaterial can also be used as substitute to EPS geofoam blocks as geofoam blocks cannot be used to fill irregular shapes, volumes and as per site requirement [8].

The current study focuses on the compressive strength behavior of plastic strips cut from the used and wasted plastic water bottles and EPS beads reinforced geomaterial using bottom ash and ordinary Portland cement as binding material. The effect of different mix ratios, plastic strip percentages and curing periods on compressive strength, stress-strain behaviour, density and initial tangent modulus of the geomaterial were studied and the results are incorporated in the paper.

\section{Characterizations of Materials}

For preparing newly developed geomaterial, bottom ash was reinforced with plastic strip cut from the waste water bottles, EPS beads and ordinary Portland cement. The bottom ash used in the experimental study had specific gravity $(G)$ of 1.91 , coefficient of uniformity $\left(C_{u}\right)$ of 3.64 , coefficient of curvature $\left(C_{c}\right)$ of 0.971 . From standard Proctor test results, the maximum dry unit weight $\left(\gamma_{\text {dmax }}\right)$ was $13.7 \mathrm{kN} / \mathrm{m}^{3}$ and optimum moisture content (OMC) was $30 \%$. The density of the EPS beads used in the study was $22 \mathrm{~kg} / \mathrm{m}^{3}$ and they were spherical in shape. A scanning electron microscope study was carried out to know the morphology of EPS beads. Figure 1 shows scanning electron micrograph of EPS bead. The diameter of EPS beads used in the present study was in the range of $2-3 \mathrm{~mm}$ and they are well rounded, spherical in shape with rough surface containing pores. By manually cutting the used waste plastic water bottles with the help of scissors in various aspect ratios of 10 and 5, plastic bottle strips were obtained.

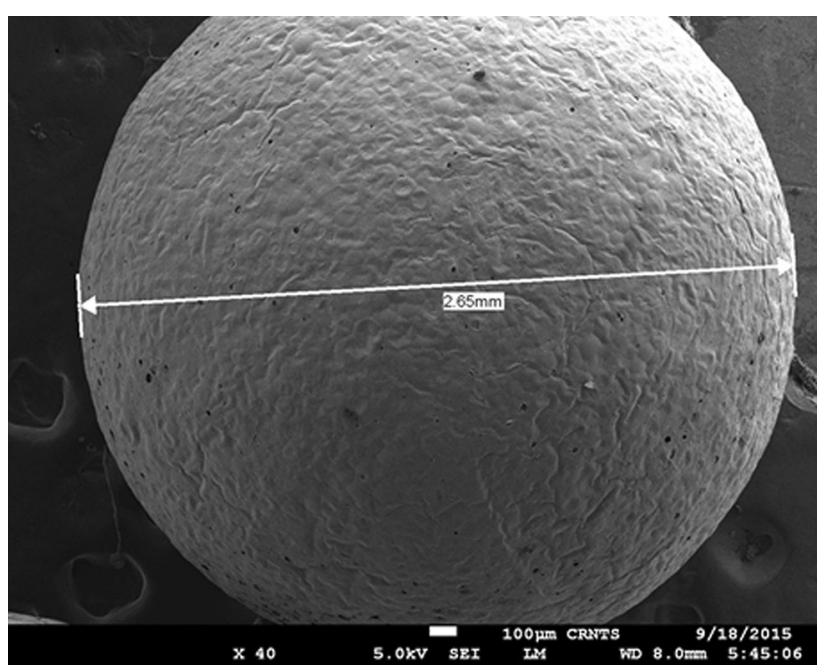

Fig. 1 Scanning electron micrograph of EPS bead

Aspect ratio is the ratio between length and width of plastic strip. The plastic strips cut from the used waste plastic water bottles were having dimensions $2 \times 20 \mathrm{~mm}^{2}$ $(\mathrm{AR}=10)$ and $4 \times 20 \mathrm{~mm}^{2}(\mathrm{AR}=5)$ as shown in Fig. 2 . The tensile strength of plastic strips cut from used and wasted plastic water bottles was obtained from cut strip test as per [9]. The tensile strength of plastic strips was $13 \mathrm{kN} /$ $\mathrm{m}$. Ordinary Portland cement of Grade 43 [10] was used in the experimental study as binding material.

\section{Experimental Program}

Compressive strength tests were carried out to investigate compressive strength of bottom ash reinforced with different mix proportions of EPS beads and plastic strip percentages for curing periods of 7,14 and 28 days.

\section{Mix Ratios and Preparation of Specimen}

The ratio between weights of EPS beads and bottom ash is called as mix ratio and in the present study these were expressed in terms of percentages. Previous Research Works carried out by $[8,11,12]$ are the basis for mix ratio calculation. $W_{B A}$, the dry weight of the bottom ash required to prepare geomaterial specimen was determined by multiplying maximum dry unit weight of bottom ash $\left(\gamma_{d \max }\right)$ by volume of dry bottom ash $\left(V_{B A}\right) . V_{B A}$ is calculated using formula $V_{B A}=V-V_{b}-V_{p s}$, where $V$ is total volume of specimen (197 cc), $V_{b}$ is volume of EPS beads and $V_{p s}$ is the volume of used and wasted plastic water bottle strips. The formula $W_{b}=\rho_{b} \times V_{b}$ gives weight of beads, where $\rho_{b}$ is density of EPS beads. $V_{b}, V_{p s}$ were considered as $20 \mathrm{cc}$ in order to achieve the weight of EPS beads required for initial mix ratio value of $0.2 \%$. Plastic strips cut from 

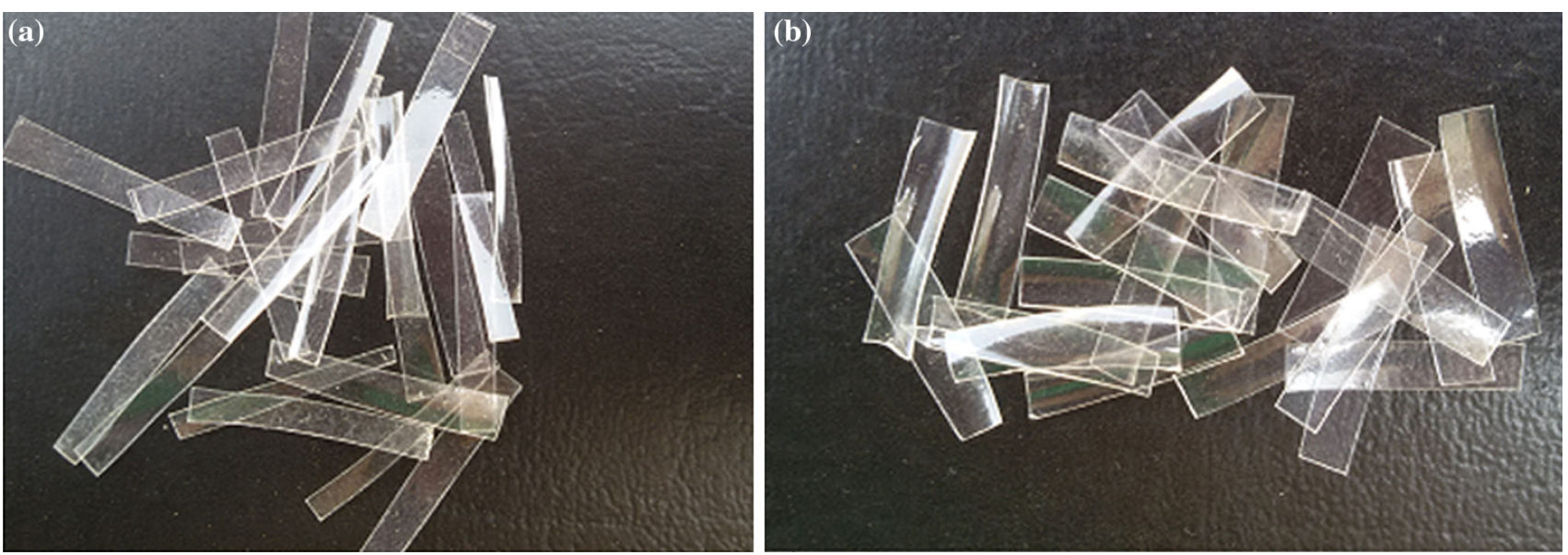

Fig. 2 Photograph of plastic strips cut from used and wasted plastic water bottles. a Aspect ratio $=10\left(2 \times 20 \mathrm{~mm}^{2}\right)$ and $\mathbf{b}$ aspect ratio $=5$ $\left(4 \times 20 \mathrm{~mm}^{2}\right)$

used and wasted plastic water bottles were added with different percentages as 1,2 and $3 \%$ with respect to weight of bottom ash and it is denoted in the experimental program as weight of plastic strips to bottom ash ( $P S / B A)$. Two different aspect ratios, 10 and 5, were used in the experimental program. Weight of cement to weight of bottom ash ratio $(C / B A)$ was taken as constant $10 \%$ and kept constant for all the samples. The quantity of water to be added for the preparation of specimen was calculated by multiplying OMC of bottom ash with weight of dry bottom ash $V_{W}=W_{B A} X$ OMC. In the same manner, the remaining mix ratios and weight of materials were calculated. The various mix ratios used in the experimental program is given in Table 1.

After weighing all the materials required for preparing the geomaterial using an electronic weighing balance, bottom ash and cement were blended thoroughly to make uniform mass. The required amount of water was added gradually to make bottom ash cement mixture. Later, plastic strips and EPS beads of required quantity were added and then mixing was continued. The mixture was casted into steel cylindrical moulds with help of trowel and allowed for $24 \mathrm{~h}$ for initial setting. The geomaterial specimens were removed after initial setting period from the mould and then kept in

Table 1 Different mix ratios used in the experimental program

\begin{tabular}{lll}
\hline Mix ratios (\%) & $\begin{array}{l}\text { Plastic strips }(P S / B A)(\%) \\
\text { Aspect ratios: } 10,5\end{array}$ & Cement $(C / B A)(\%)$ \\
\hline 0.2 & $1,2,3$ & 10 \\
0.4 & $1,2,3$ & 10 \\
0.6 & $1,2,3$ & 10 \\
0.8 & $1,2,3$ & 10 \\
1.0 & $1,2,3$ & 10 \\
\hline
\end{tabular}

water tank for curing. Figure 3 shows mixing of material to prepare the specimens and curing of specimens in tank. Experimental program had curing periods of 7, 14, 28 days.

\section{Test Procedure}

By using an electronic weighing balance, each specimen was weighted after air drying. Compressive strength was measured by performing compression tests on specimens with the help of compressive testing machine with a constant strain rate of $0.12 \mathrm{~mm} / \mathrm{min}$. Linear variable differential transducer (LVDT) was used to measure the deformation. Compressive load was measured by a load cell. LVDT and load cell were connected to a data logger and were calibrated before testing. Two numbers of specimens were prepared and tested for each mix ratio with each aspect ratio and for a particular plastic strip percentage. A total number of 180 specimens were prepared and tested for the compressive strength and the results are incorporated in the paper.

\section{Results and Discussion}

\section{Density}

The bulk density of the geomaterial prepared with different mix ratios was calculated by dividing the weight of the prepared geomaterial specimen just before testing with volume of the specimen. The effect of mix ratios on density of geomaterial for both aspect ratios is shown in Fig. 4. The relationship between density and mix ratio values was found to be linear for each aspect ratio. The density of geomaterial was higher when aspect ratio was 5 

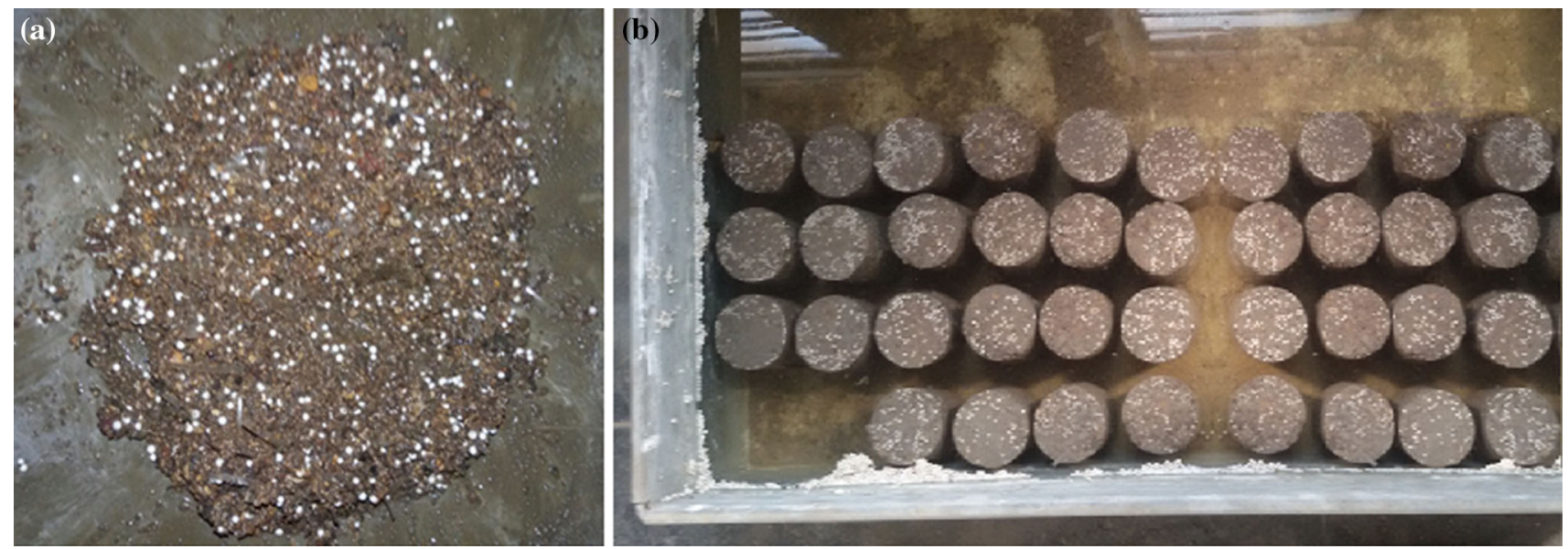

Fig. 3 Photograph of a mixing of different material and $\mathbf{b}$ curing of specimens in tank
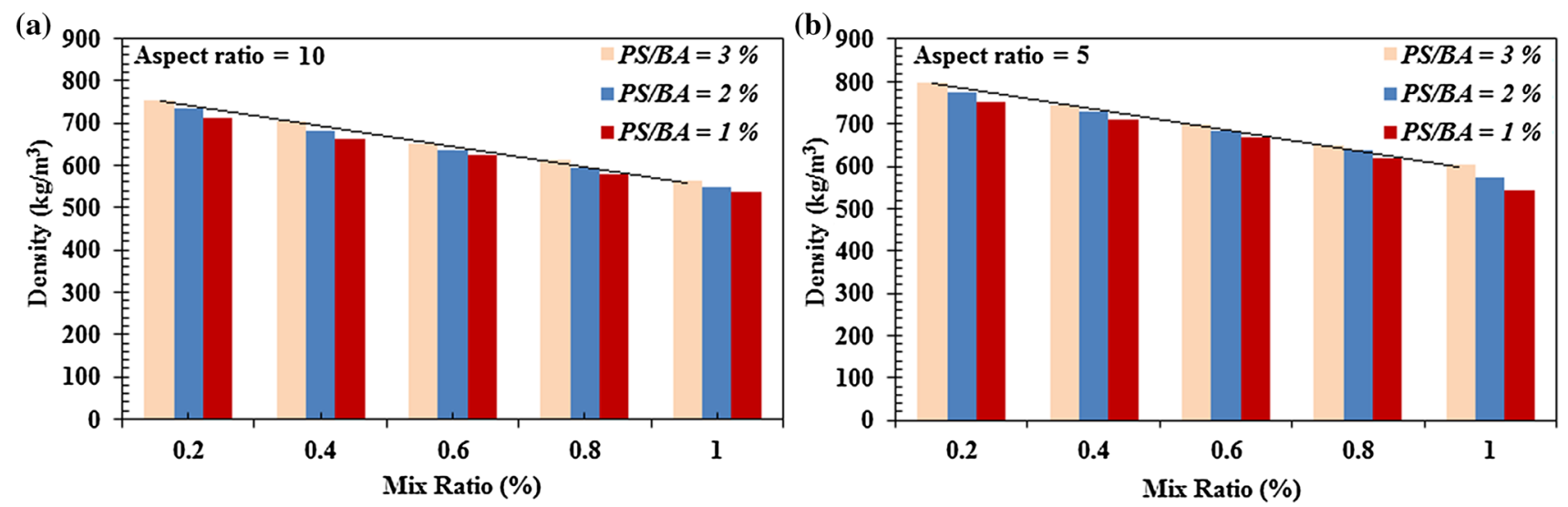

Fig. 4 Effect of mix ratios on density of geomaterial for both aspect ratios. $\mathbf{a}$ Aspect ratio $=10$ and $\mathbf{b}$ aspect ratio $=5$

and $P S / B A$ was $3 \%$ for each mix ratio value. Increase in the density may be because increase in $P S / B A$ value increases the weight of the geomaterial specimen. For a particular mix ratio value, weight of the plastic strips to prepare the geomaterial specimen was increased with increasing $P S / B A$ ratios. With increasing mix ratio values for each $P S / B A$ ratio, the density values of geomaterial were decreased. The density values for all mix ratios, aspect ratios and $P S / B A$ values are in range of $500-800 \mathrm{~kg} / \mathrm{m}^{3}$. Increasing the mix ratio value to $0.2 \%$ can result in $5.19-7.11 \%$ decrease in the density of geomaterial. The density values achieved in the present study are in the range of light weight fill material density $700-1100 \mathrm{~kg} / \mathrm{m}^{3}$ as reported by [11] and $725-1320 \mathrm{~kg} / \mathrm{m}^{3}$ as reported by [13]. The density values from the present study are higher than the density values $435-650 \mathrm{~kg} / \mathrm{m}^{3}$ as reported by [8]. The density values achieved in the present study is lower than that of conventional fill material, which lies between 1700 and $1900 \mathrm{~kg} / \mathrm{m}^{3}$ as reported by [11]. This is significant improvement in terms of density values.

\section{Failure Patterns}

The failure patterns of bottom ash reinforced with EPS beads and plastic strips based geomaterial under the action of axial compressive load were observed. All the specimens failed in axial strain range of $0.65-1.8 \%$. Before failure, vertical and diagonal cracks were observed in the specimens. The failure pattern of EPS beads and plastic strips reinforced geomaterial is shown in Fig. 5.

\section{Compressive Strength}

After 7, 14 and 28 days of curing period, the compression tests on specimens was conducted. In the newly developed geomaterial, compressive strength was significantly influenced by the aspect ratio, plastic strip percentages, mix ratio values and curing periods. The peak value of compressive stress was considered as compressive strength. Figure 6 shows the variation of compressive strength measured for the reinforced bottom ash specimens with respect to mix ratio values for different $P S / B A$ ratios and 


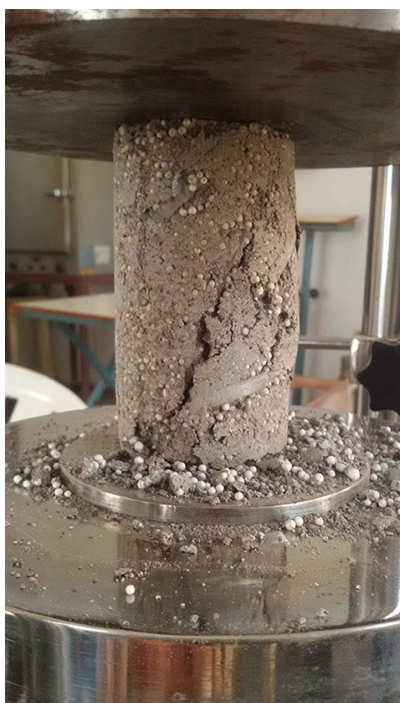

Fig. 5 Failure pattern of EPS beads and plastic strips reinforced geomaterial

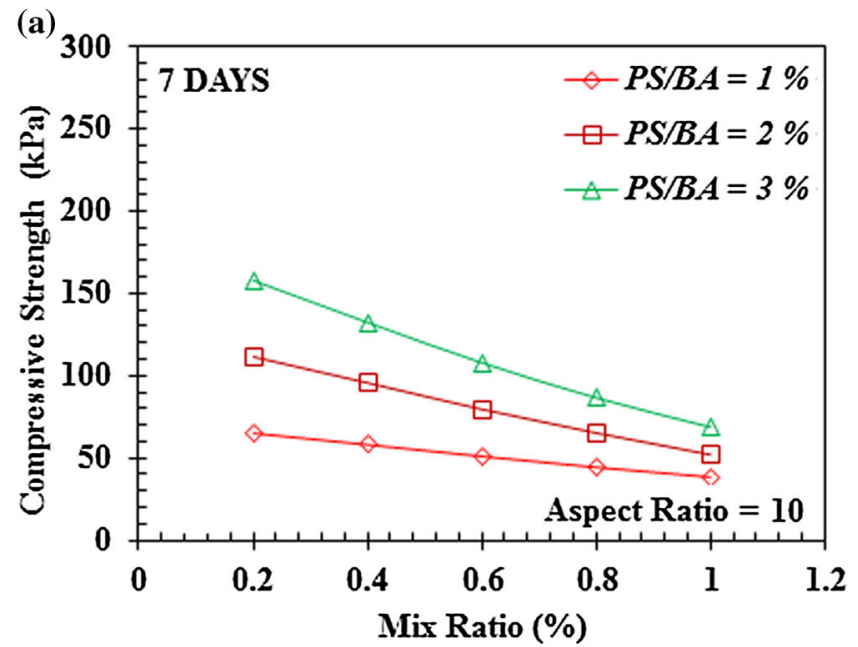

all curing periods for aspect ratio 10. Linear relationship was observed between compressive strength and mix ratio values for all $P S / B A$ ratios and curing periods. For each $P S /$ $B A$ ratio and aspect ratio, the maximum compressive strength was observed at mix ratio value of $0.2 \%$ and compressive strength linearly decreased to its minimum value at mix ratio value of $1.0 \%$. The compressive strength values from mix ratio of $0.2 \%$ starts converging towards mix ratio of $1.0 \%$. The compressive strength was highest at $P S / B A$ ratio $3.0 \%$ and decreased to a lowest value when $P S / B A$ ratio $1.0 \%$ for all aspect ratios. This is due to the fact that inclusion of plastic strips in geomaterial specimen increased the compressive strength as well as increased the amount of deformation it underwent before failure, that is ductility. For both aspect ratio values and $P S / B A$ values and all mix ratios, the increase in the compressive strength values from 7 to 28 days curing period is

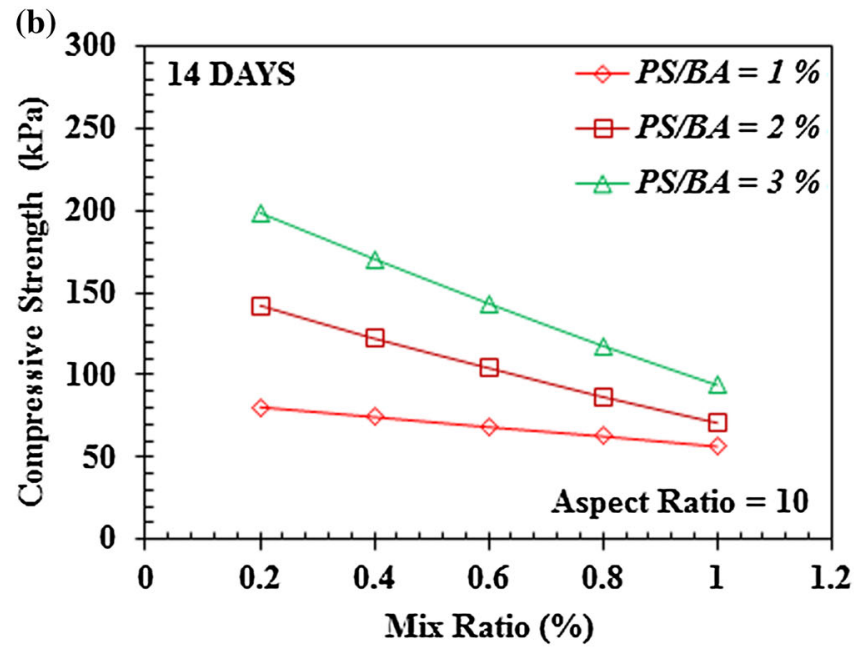

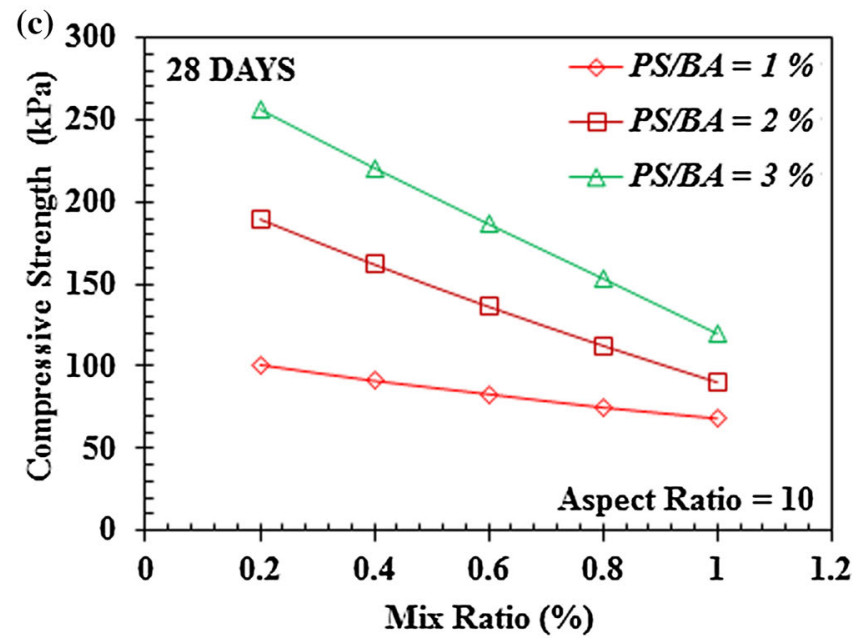

Fig. 6 Relationship between compressive strength and mix ratios of aspect ratio 10 for different curing periods a 7 days, b 14 days and c 28 days 
in the range of $35-55 \%$. Similar trend was observed with aspect ratio 5 as shown in Fig. 7.

The relationship between compressive strength and PS/ $B A$ ratio for both the aspect ratio values at 28 days curing period is shown in Fig. 8. Linear relationship between compressive strength and $P S / B A$ values was observed. For each Aspect ratio, compressive strength of geomaterial increased with increase in $P S / B A$ value. For each $P S / B A$ value, aspect ratio 5 produced higher compressive strength value as compared to that with aspect ratio 10 . Similar trend was observed for other curing periods. The compressive strength values of prepared geomaterial were in the range of $38-257 \mathrm{kPa}$ for aspect ratio 10 and 54$294 \mathrm{kPa}$ for aspect ratio 5. Table 2 gives the compressive strengths of all mix ratios for both aspect ratios with each $P S / B A$ ratio and curing period. For each curing period, increase in the $P S / B A$ value increases the compressive strength. Figure 9 shows the correlation between density $(\rho)$ and compressive strength $(\sigma)$ of geomaterial for both aspect ratios. The correlation is best fitted to a polynomial function and is given by

$\sigma=0.002 \rho^{2}-1.9704 \rho+542.56$

where $\sigma$ is in $\mathrm{kPa}$ and $\rho$ is in $\mathrm{kg} / \mathrm{m}^{3}$.

\section{Stress-Strain Pattern}

The stiffness properties and stress-strain characteristics of geomaterial were evaluated from the data obtained by compressive strength tests carried out on geomaterial. The relationship between compressive stress and axial strain for all mix ratios, $P S / B A$ values, aspect ratios, 10 and 28 days curing period is shown in Fig. 10. The relationship between compressive stress and axial strain was observed to be nonlinear for all $P S / B A$ percentages. For particular mix ratio and curing period, the stiffness of geomaterial (a)

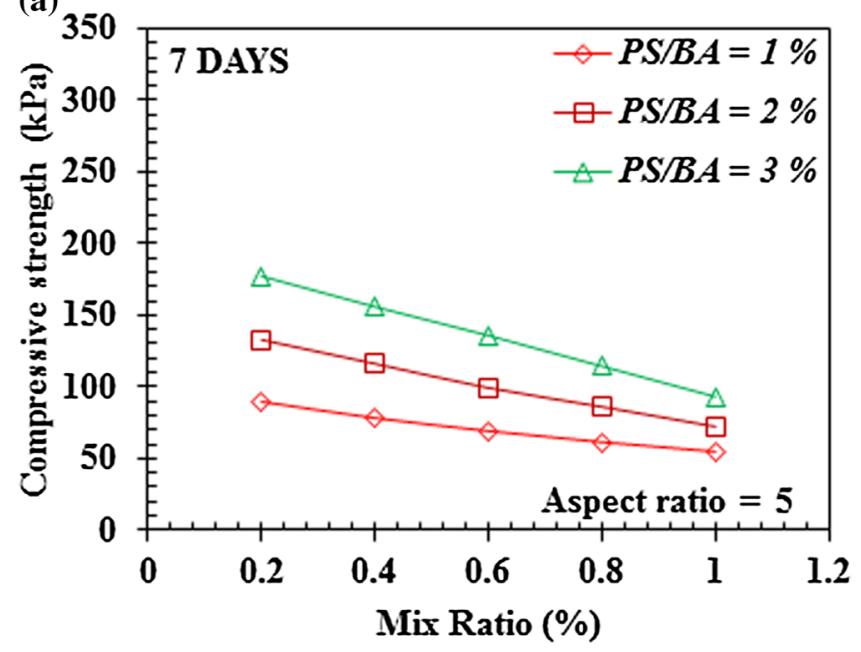

(b)

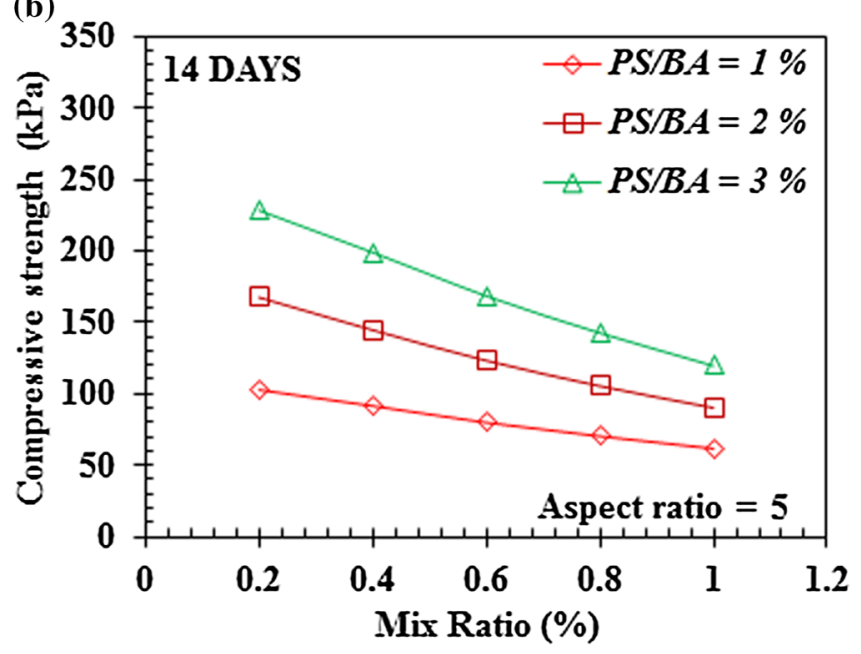

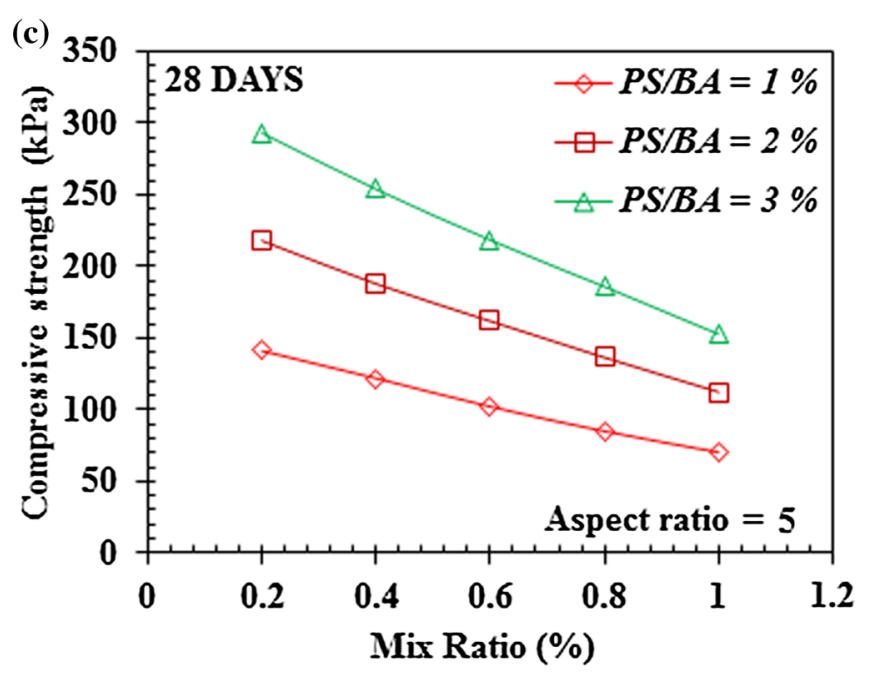

Fig. 7 Relationship between compressive strength and mix ratios of aspect ratio 5 for different curing periods a 7 days, b 14 days and $\mathbf{c} 28$ days 


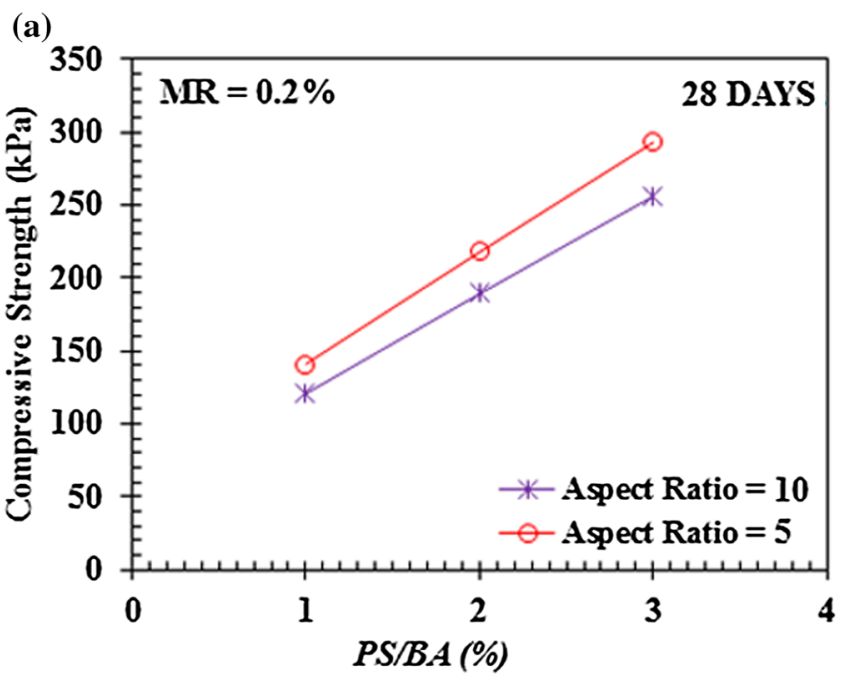

(b)
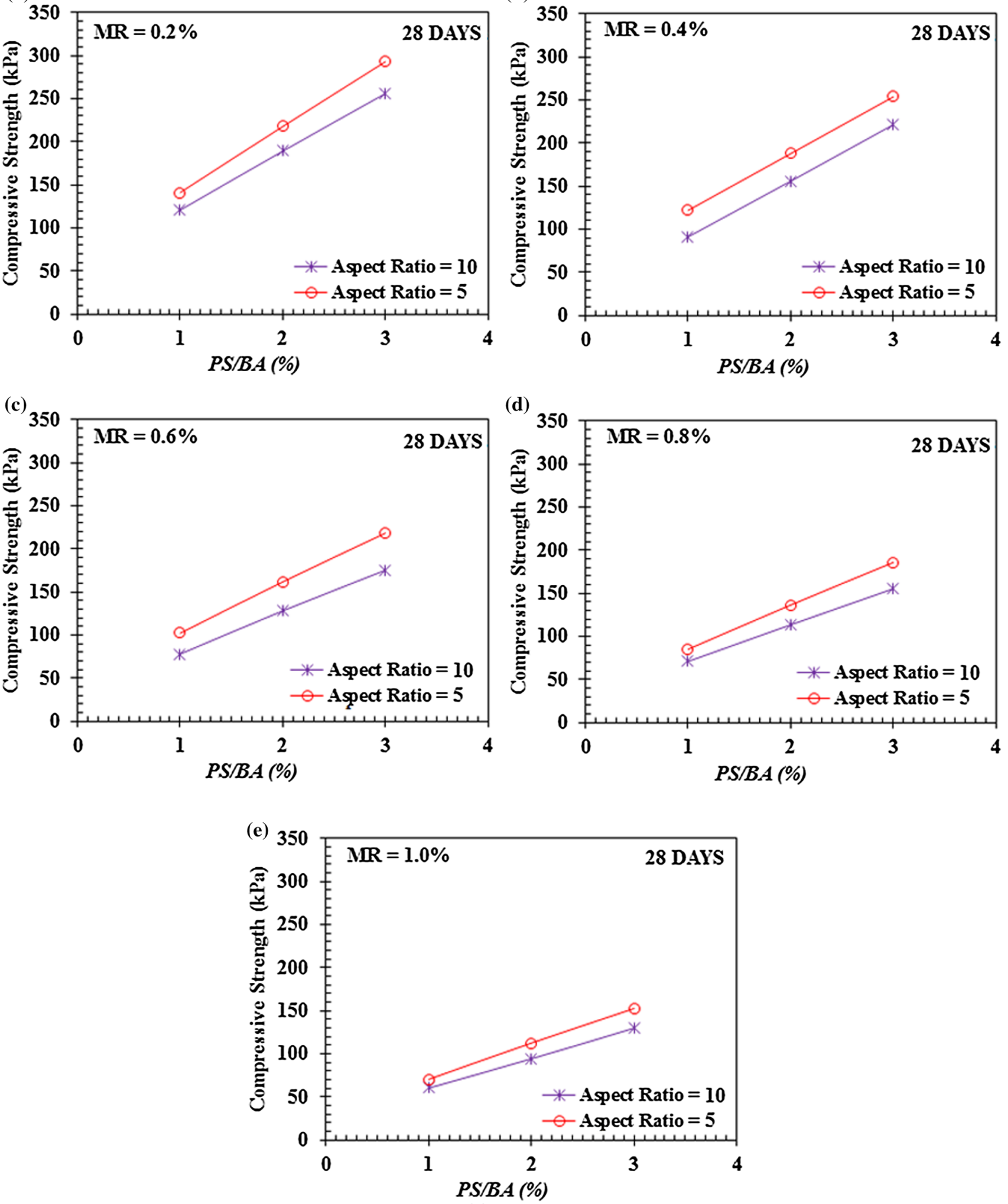

(e)

Fig. 8 Relationship between compressive strength and $P S / B A$ ratio values for 28 days curing period 


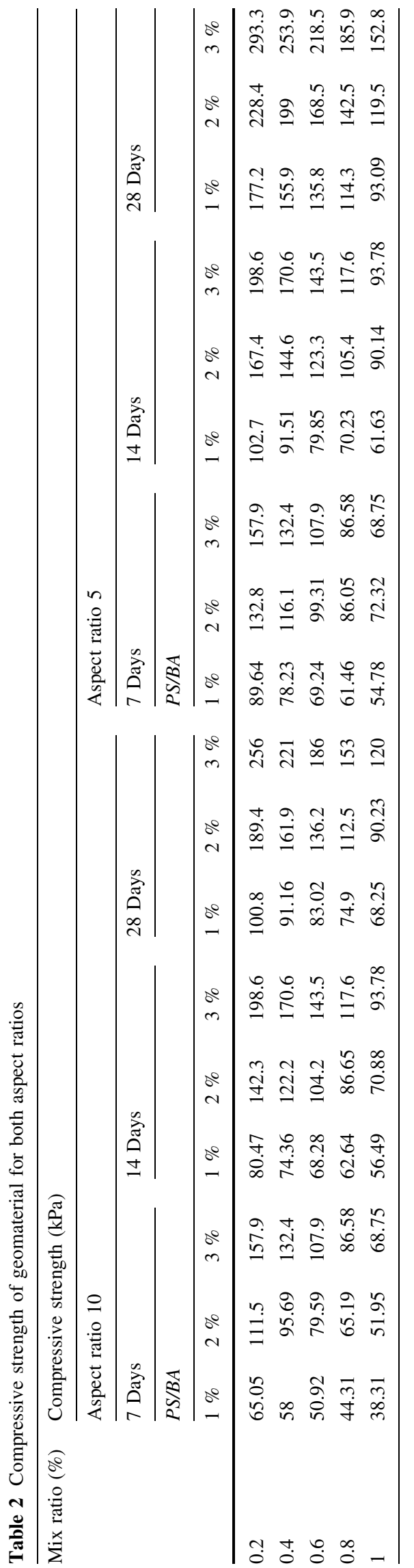

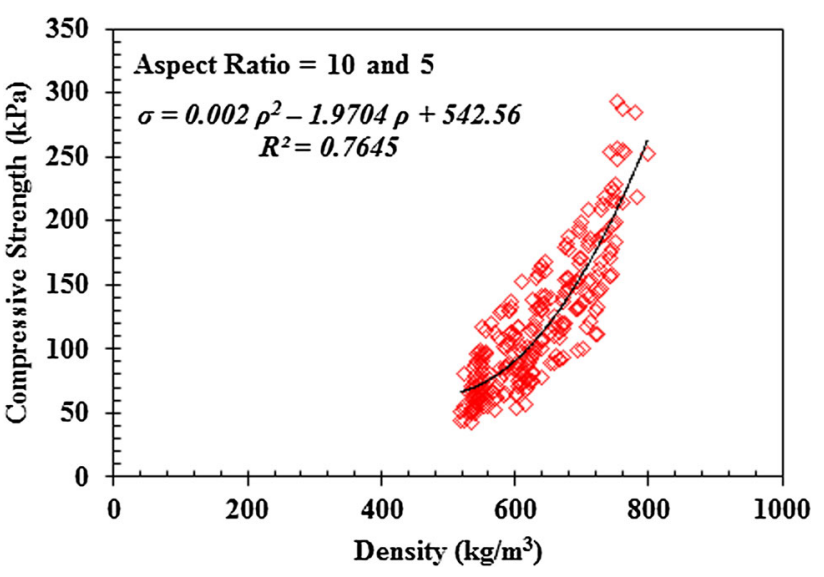

Fig. 9 Correlation between density and compressive strength of geomaterial for both aspect ratios

increased with increasing $P S / B A$ values. The stiffness of newly developed geomaterial was found to be higher when aspect ratio was 5 for each mix ratio, $P S / B A$ ratio and all curing periods. The $P S / B A$ value of $3.0 \%$ shows higher stiffness and compressive strength for both aspect ratios. Hence, it can be said that the compressive strength and stress-strain behaviour of geomaterial were significantly influenced by the aspect ratio and $P S / B A$ ratio values. Similar trend was observed for aspect ratio 5 as shown in Fig. 11. Figure 12 shows the relationship between compressive stress and axial strain for all mix ratios, $P S / B A$ values, aspect ratios, 10 and 28 days of curing period. Nonlinear relationship was observed between compressive stress and axial strain for all mix ratios and curing periods. Similar patterns were observed even for aspect ratio 5 .

\section{Initial Tangent Modulus}

Initial tangent modulus $\left(E_{i}\right)$ is one of the important parameter of the newly developed geomaterial because it characterizes the stiffness of material. The slope of the tangent line to the origin of the compressive stress and axial strain curve was termed as the initial tangent modulus. The compressive strength of geomaterial increases with increasing initial tangent modulus values. In the present study, the $E_{i}$ values were in the range of 6-45 MPa. The relationship between compressive strength and initial tangent modulus of geomaterial for all $P S / B A$ ratios and $C /$ $B A$ ratio $10 \%$ is shown in Fig. 13. The correlation between initial tangent modulus $\left(E_{i}\right)$ and compressive strength $(\sigma)$ can be expressed as

$E_{i}=1.3803 \sigma^{0.8522}$

where $E_{i}$ is in $\mathrm{MPa}$ and $\sigma$ is in $\mathrm{kPa}$.

The initial tangent modulus values from the present study are in range of initial tangent modulus values of 
(a)

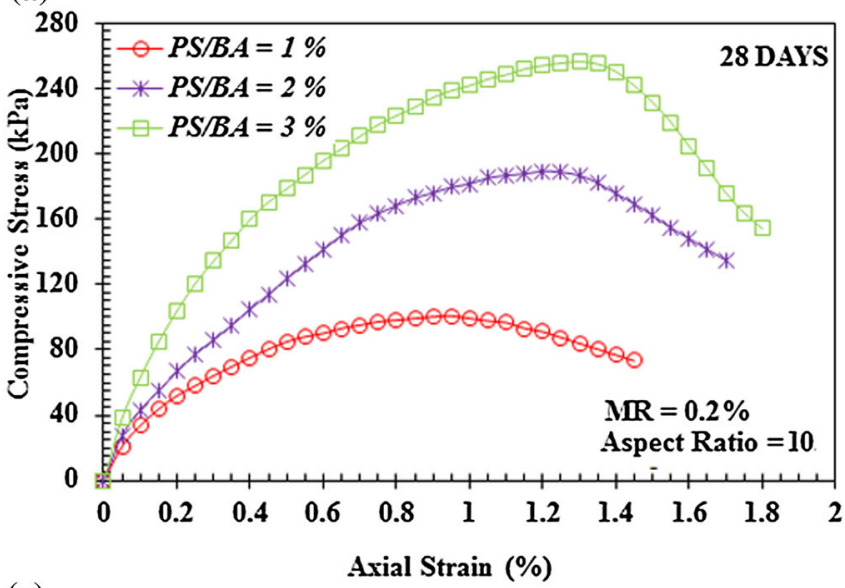

(c)

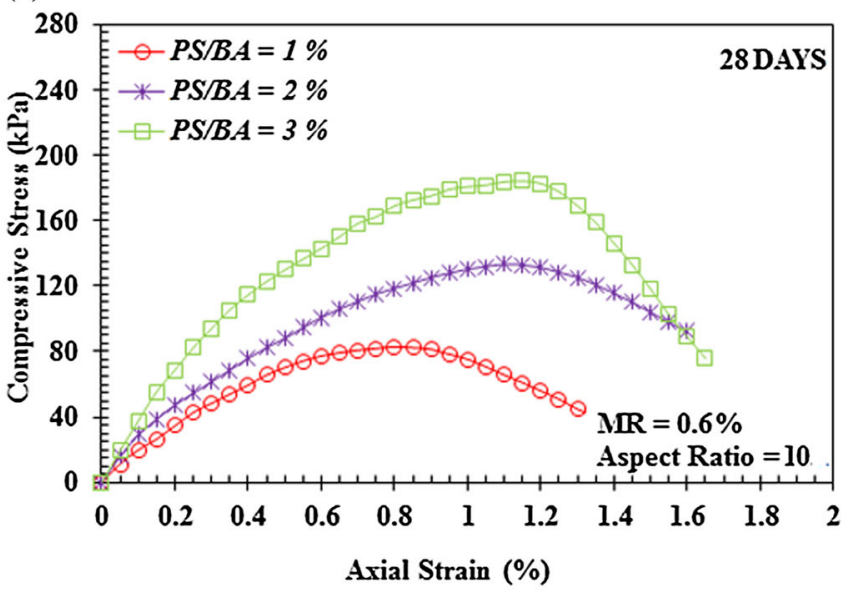

(b)

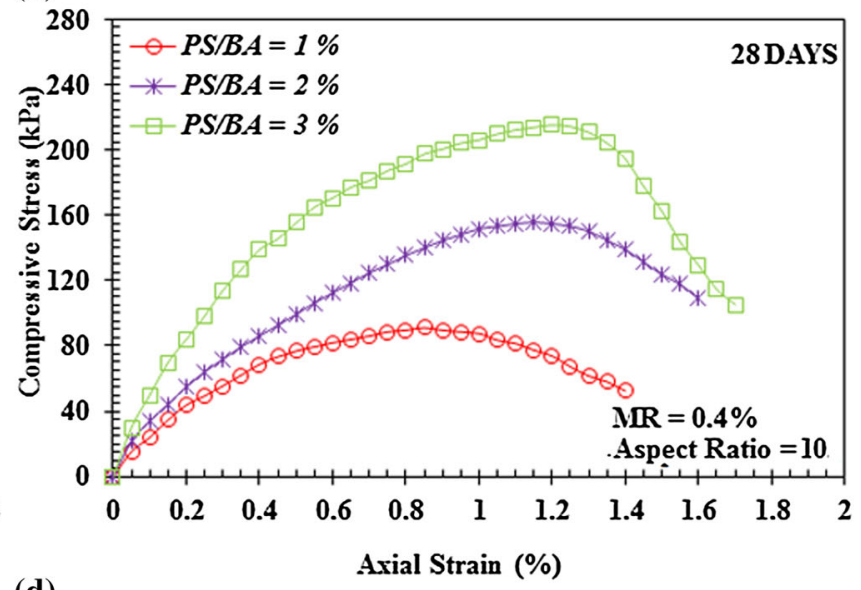

(d)

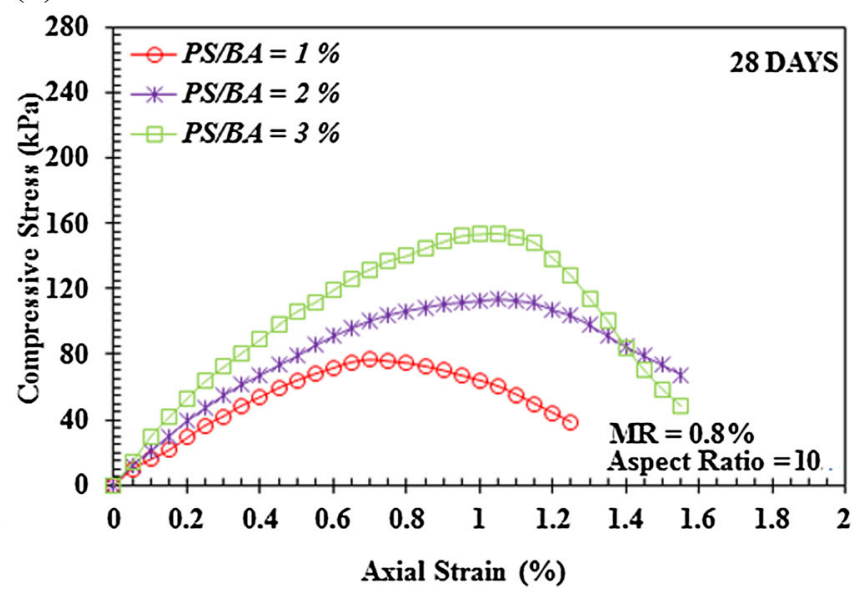

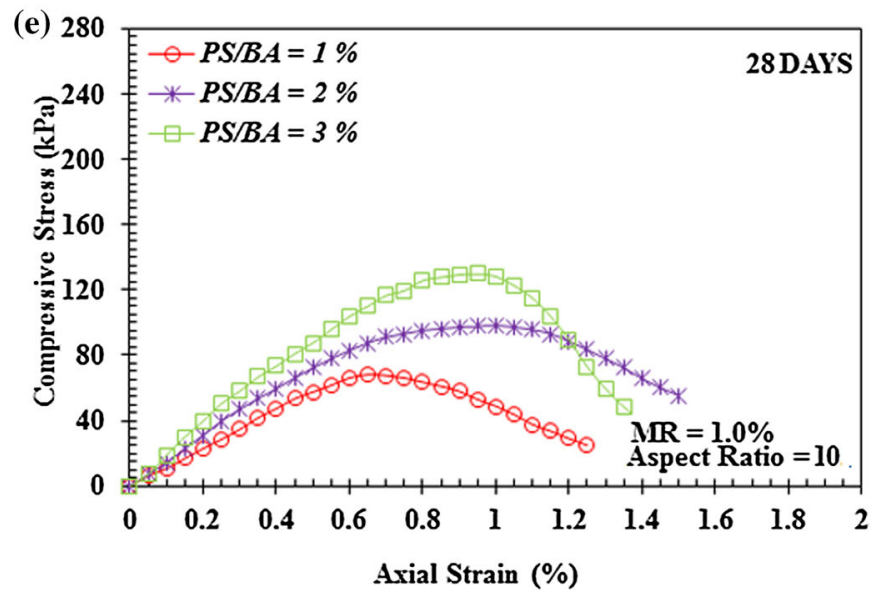

Fig. 10 Compressive stress and axial strain curves for 28 days curing period with aspect ratio 10 for all the mix ratios a $0.2 \%$ b $0.4 \%$ c $0.6 \%$ d $0.8 \%$ e $1.0 \%$

geomaterial 15-42 MPa as reported by [8] and lower than that of light weight fill material 79-555 MPa as reported by [11]. The initial tangent modulus from the present study was higher than that of EPS geofoam block, which lies between 2.2 and $11.4 \mathrm{MPa}$ as reported by $[14,15]$.

\section{Conclusions}

An experimental study was carried out on newly developed geomaterial to know its behaviour under compressive load. The density, compressive strength, stress-strain behaviour 

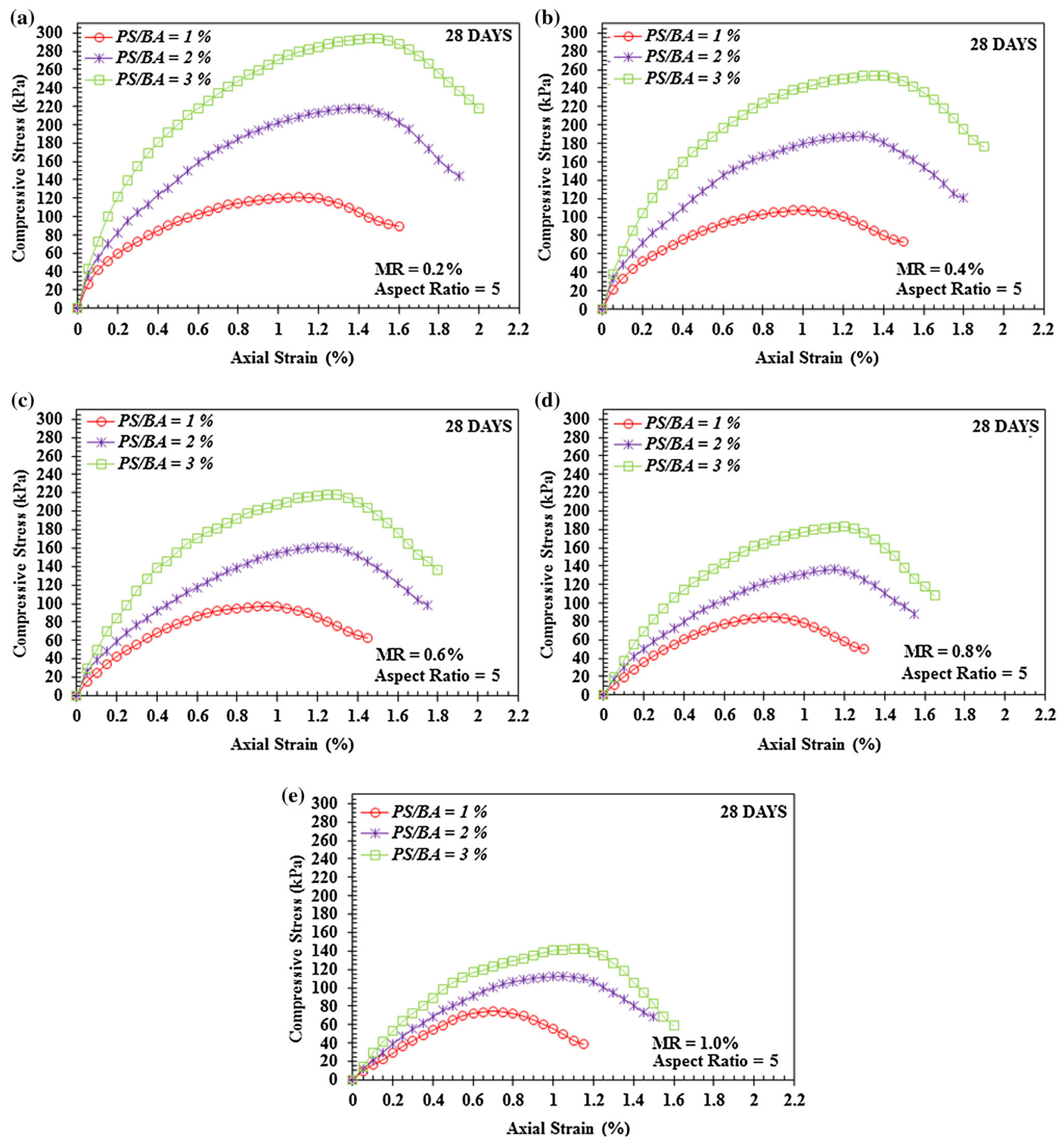

Fig. 11 Compressive stress and axial strain curves for 28 days curing period with aspect ratio 5 for all the mix ratios a $0.2 \%$ b $0.4 \%$ c $0.6 \%$ d $0.8 \%$ e $1.0 \%$

and initial tangent modulus of the geomaterial were significantly influenced by mix ratio values, plastic strip percentages and curing periods. From the study, following conclusions are drawn.

1. For a particular mix ratio value, the density of geomaterial increased with increasing $P S / B A$ values.
The density values for all mix ratios and $P S / B A$ values are in range of $500-800 \mathrm{~kg} / \mathrm{m}^{3}$. Increasing the mix ratio value to $0.2 \%$ can result in $5.19-7.11 \%$ decrease in the density of geomaterial. For each mix ratio value, the higher density was found out for aspect ratio 5 as compared to aspect ratio 10 . 
(a)

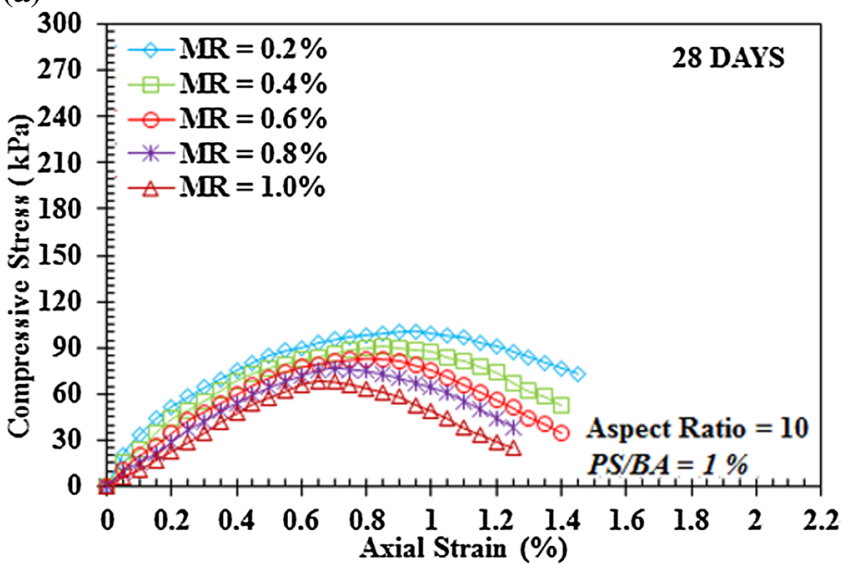

(b)

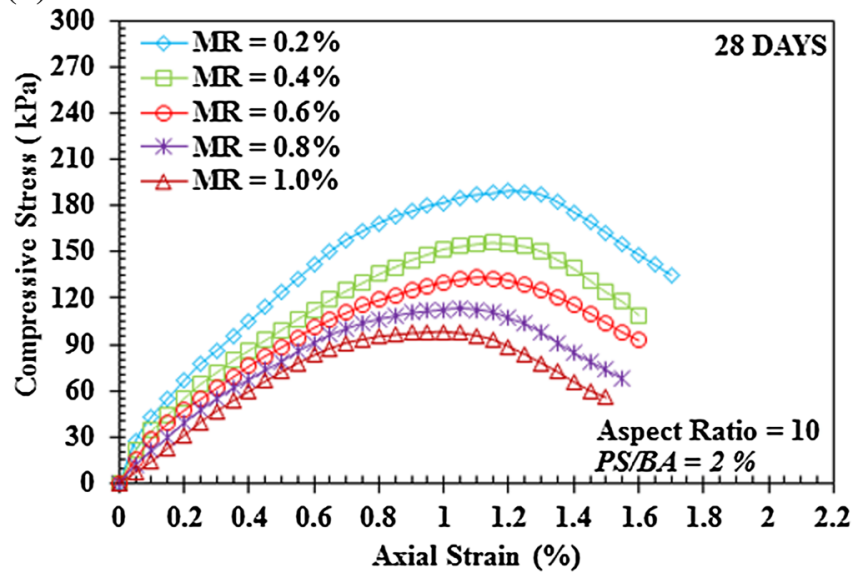

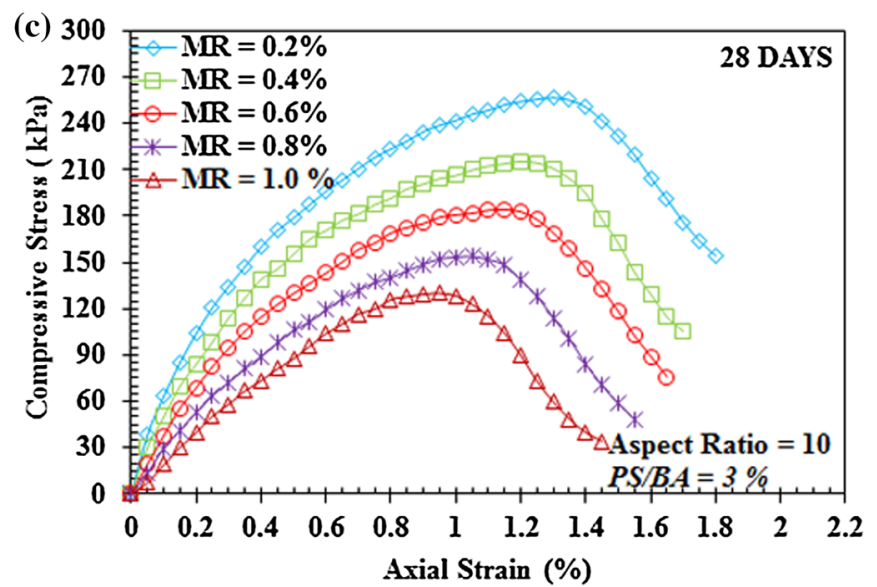

Fig. 12 Compressive stress and axial strain curves for 28 days curing period with aspect ratio 10 for all $P S / B A$ percentages a $1 \%$, b $2 \%$ and c $3 \%$

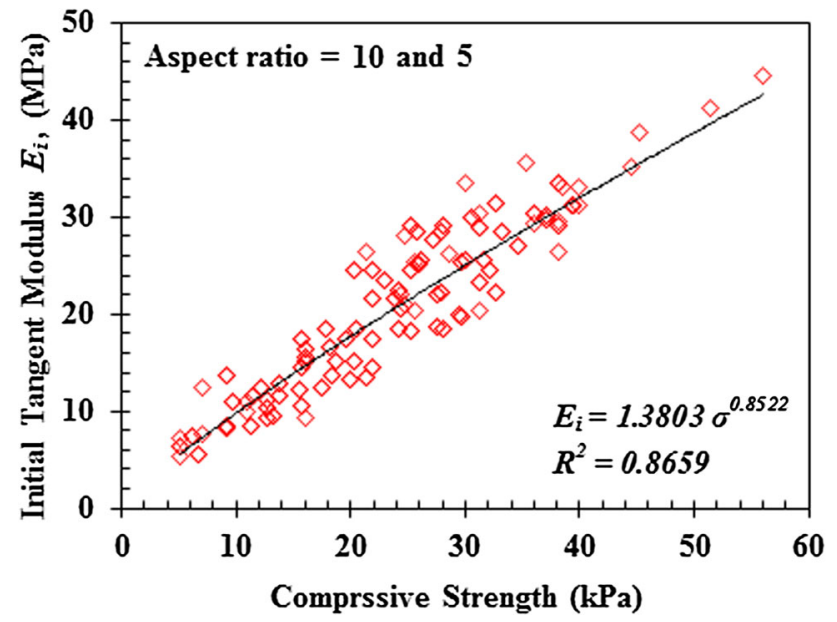

Fig. 13 Correlation between compressive strength and initial tangent modulus of geomaterial for all $P S / B A$ ratios

2. The relationship between compressive strength and mix ratio values was observed to be linear for all $P S / B A$ ratios and for all the curing periods. With increasing aspect ratio, $P S / B A$ ratio and curing periods, the compressive strength of geomaterial increased. For $P S / B A$ ratio $3.0 \%$, higher compressive strength was observed. The compressive strength values got significantly influenced by the mix ratios and curing period. The compressive strength values of prepared geomaterial were in the range of 38-257 kPa for aspect ratio 10 and 54-294 kPa for aspect ratio 5. Maximum compressive strength was observed when mix ratio was $0.2 \%$.

3. Non-linear stress-strain relationships were observed and all the specimens failed in axial strain range of 0.65-1.8\%. When $P S / B A$ was $3.0 \%$, higher stiffness and compressive strength of geomaterial was observed for both aspect ratios.

4. The initial tangent modulus of the geomaterial increased with increasing compressive strength. The initial tangent modulus of geomaterial was in the range of 6-45 MPa with respect to curing periods.

Acknowledgments The authors wish to express their sincere thanks to the Editor and to the reviewers for their invaluable suggestions and comments in improving the quality of the paper. 


\section{References}

1. Prakash K, Sridharan A (2009) Beneficial properties of coal ashes and effective solid waste management. J Hazard Toxic Radioact Waste ASCE 13(4):239-248

2. Ghafoori N, Buchole J (1998) Investigation of lignite-based bottom ash for structural concrete. J Mater Civ Eng ASCE 8(3): 128-137

3. Central Pollution Control Board-CPCB (2012) An overview of plastic waste management. Parivesh Bhavan, Delhi, pp 1-22

4. Wang F, Miao L (2009) A proposed lightweight fill for embankment using cement treated Yangzi river sand expanded polystyrene beads. Bull Eng Geol Environ 68:517-524

5. Horvath JS (1994) Expanded polystyrene geofoam: an introduction to material behaviour. Geotext Geomembr 13:263-280

6. BASF (Badische Anilin-und Soda-Fabrik) (2004) Geofoam for construction industry in India. Technical Bulletin E7, Navi Mumbai

7. Chun BS, Lim HS, Sagong M, Kim K (2004) Development of hyperbolic constitutive model for expanded polystyrene (EPS) geofoam under triaxial compression tests. Geotext Geomembr 22(4):223-237

8. Ram Rathan Lal B, Badwaik VN (2015) Experimental studies on bottom ash and expanded polystyrene beads based geomaterial. J Hazard Toxic Radioact Waste ASCE 20(2):1-8
9. ASTM D5035-11 (2015), Standard test method for breaking force and elongation of textile fabrics (strip method). ASTM International, West Conshohocken

10. IS 8112 (1989), 43 grade ordinary portland cement-specification. Bureau of Indian Standard (BIS), New Delhi

11. Liu HL, Deng A, Chu J (2006) Effect of different mixing ratios of polystyrenes pre-puff beads and cement on the mechanical behaviour of lightweight fills. Geotext Geomembr 24:331-338

12. Marjive VR, Badwaik VN, Ram Rathan Lal B (2016) Experimental studies on controlled low strength material using stone dust and EPS beads. Int J Eng Technol 8(4):265-268

13. Padade AH, Mandal JN (2014) Expanded polystyrene-based geomaterial with fly ash. Int J Geomech ASCE 14(6):1-7

14. Horvath JS (1997) The compressible-inclusion functions of EPS geofoam: analysis and design methodologies. Geotext Geomembr 15(1):77-120

15. Padade AH, Mandal JN (2012) Feasibility studies on expanded polystyrene (EPS) geofoam. In: International conference on ground improvement and ground technique, ICGI-2012, Wollongong, vol 2, pp 903-906. 30 Oct-2nd Nov 